\title{
On the neo-Vedanta as reconceptualised by Vivekananda in his Complete Works: A cognitive linguistic analysis in light of Conceptual Metaphor Theory
}

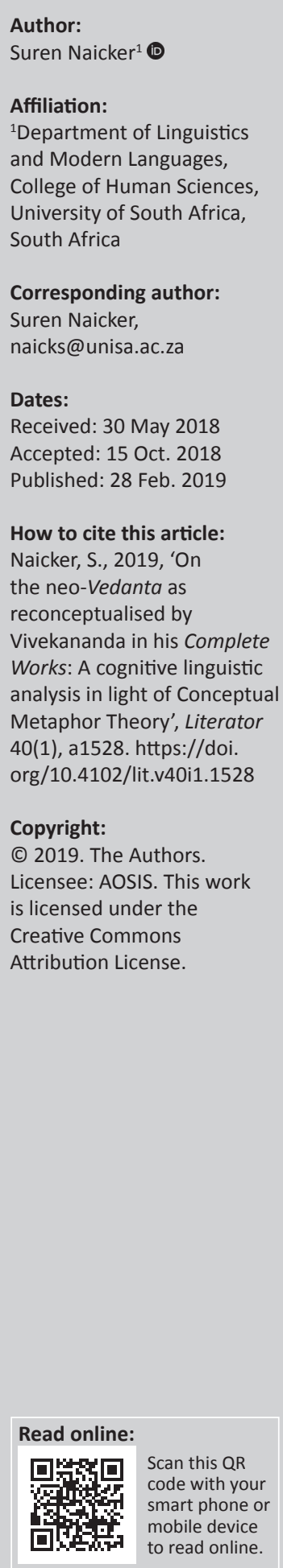

This article investigates the use of metaphorical language in The Complete Works of Swami Vivekananda (henceforth CW). Vivekananda is one of the most important modern-day Hindu scholars because his interpretation of ancient Hindu scriptural lore has been very influential. Vivekananda's influence was part of the motivation for choosing his $\mathrm{CW}$ as the empirical domain for the current study. AntConc software was used to mine Vivekananda's CW for water-related terms, which seemed to have a predilection for metaphoricity. Which terms to search for specifically was determined after a manual reading of a sample from the CW. The data were then tagged using a convention inspired by the well-known Metaphor Identification Procedure - Vrije University (MIPVU). Then, a representative sample of the data was chosen, and the metaphors were mapped and analysed thematically. Five of these are referred to in this article, but special emphasis is placed on the theme of the Vedanta philosophy as the basis for neo-Hinduism, which has become synonymous with contemporary Hinduism, with Yoga as the practical wing, and Vedanta as the ideological basis for the practice; this aspect is expounded upon in more detail. The study's main aim was therefore to investigate whether Hindu religious discourse uses metaphors to explain abstract religious concepts in a specific way, and indeed one of the main findings was the pervasiveness of water as a source domain. Hence, the key finding in this article is that neo-Hindu thought, as reconceptualised by Vivekananda, relies heavily on the water frame (as is convention in the field of Cognitive Semantics, conceptual domains are written in upper case, including hypothetical frames and conceptual metaphors), which is not as pervasive in other religio-philosophical traditions.

\section{Introduction}

The complex nature of religious discourse remains a problem worth investigating, in the sense that the language used when talking about topics within the domain of religion often has nuanced connotations. One example could be the standard meaning of 'consciousness' in Western psychology, which pertains to an embodied being's ability to respond to external stimuli. In the context of Hindu philosophy, consciousness does not have to be embodied and refers to some kind of intelligent life force that pervades the entire cosmos. Hence, when analysing different religious philosophies, there is the problem that the same words are often used to talk about very different concepts, even though there may not be any 'clear analogues' for that term (Harrison 2015:307). One salient example is the word 'God', for which there is literally no analogue in Buddhism, and the same term applied to Hindu philosophy means something very different from the Judaeo-Christian word. When speaking in English, a practising Hindu will use the word 'God'; however, 'while this conception is also found in the Indian tradition, it stands in sharp contrast to the dominant conceptualisation of knowledge found in traditional East Asian philosophies' (Harrison 2015:308). These conceptual differences are part of the problem and can stunt inter-cultural and inter-religious dialogue.

Vivekananda, in being tasked with bringing the Vedanta philosophy to the West by his guide and guru Sri Ramakrishna, was forced to bridge this gap, beginning with his maiden public address in Chicago, USA, on 11 September 1893. Given that the audience comprised many representatives from the Western intelligentsia, including Jewish and Christian religious leaders, Vivekananda had to find a way of being intelligible and, therefore, had to adopt the standard Western frame of reference in his discourse.

Note: This article is partially based on the author's thesis for the degree of Doctor of Literature and Philosophy, in the subject Linguistics, at the University of South Africa, South Africa, with promoter Dr B.E. Zawada and co-promoter Prof. A.C. Wilsenach, received November 2016, available here: http://uir.unisa.ac.za/bitstream/handle/10500/22281/thesis_naicker_s.pdf?isAllowed=y\&sequence=1 
One of the strategies employed by Vivekananda was to start off with reference to something that the audience was almost certainly familiar with - something known, something concrete. Sometimes it would be a parable, sometimes an excerpt from the Bible, and often it would be via some kind of analogy with a natural object, concept or phenomenon. The latter led Vivekananda to employ a number of metaphors in expounding upon his philosophy, defined as understanding 'abstract aspects of our experience by means of mapping them onto domains of experience which are more concrete' (Harrison 2015:313).

Within the context of Lakoff and Johnson's conceptual metaphor theory (CMT), it is understood that metaphors are conceptual in nature, and they therefore have a direct 'effect on our thought, experience, and on our everyday activity' (Harrison 2015:309). Harrison also claims that 'different conceptual metaphors underlie the practice of philosophy within different cultures' (p. 309). Conceptual metaphor theory is closely associated with the paradigm of embodied realism, which claims that because the mind is embodied, there will be similar primary metaphors across cultures simply because of the 'similarity of human bodies, physical environments, and experience' (Harrison 2015:311). Given the importance of 'conceptual metaphor theory, we would expect to find that philosophising, wherever and whenever it occurs, is a complex activity structured by a range of (not necessarily consistent) metaphors' (Harrison 2015:311). It may also be worth noting that 'Lakoff and Johnson's work has enjoyed a more far-reaching impact within religious studies than it has within philosophy' (Harrison 2015:321). This makes CMT an apt framework for the current study, which aims to explore the kinds of metaphors Vivekananda, as an influential Hindu philosopher, employed.

Here, a brief mention should be made about Vivekananda: Swami Vivekananda was a Bengali saint and social reformer. He was the disciple of the well-known Bengali mystic Sri Ramakrishna. Following Sri Ramakrishna's death in 1886, Vivekananda, upon Ramakrishna's instruction, led a group of young disciples and founded what is now known as the Ramakrishna Math and Mission, 'whose wide spreading branches offer shelter and solace to millions all the world over' (Prabhananda 2009:iii). Indeed, the Ramakrishna Math and Mission has grown to become one of the largest and most influential Hindu organisations in the world. Furthermore, Vivekananda deviated from orthodoxy by starting a new order of monkhood, the Ramakrishna Order of Monks. Until this point, females were not allowed to be initiated as monks, and people of lower castes were also barred from entering monastic life. Vivekananda changed that, and many influential religious leaders after him followed suite, like Swami Sivananda, founder of the Divine Life Society, Sri Aurobindo and Paramahamsa Yogananda. It is in this context that this article refers to Vivekananda's ideas as having 'reconceptualised' orthodox Hinduism as a whole and introduced what can be called neo-Vedanta, which places emphasis on the Vedanta philosophy specifically (as opposed to the many other schools of thought within the tradition), which will be outlined below.
The headquarters of the Ramakrishna Math and Mission is known as Belur Math and is located in the northern region of Kolkata, India. The South African headquarters is located in Glen Anil, Durban, with various branches all over the country. Hence, as the first key figure to cross the East-West spiritual-intellectual divide, an analysis of the strategies he used to bring his ideas to the populace is worthy of investigation - hence the rationale behind the current study.

It is with this in mind that the current study was undertaken, and given the facts above, including Vivekananda's mandate to bring the Vedanta philosophy to the West; the specific research question underlying this study is as follows: 'What are the specific metaphors that Vivekananda used to explain the nuances of the Vedanta philosophy in bringing it to the West?' Of course, it is assumed at the outset that there will be a proliferation of metaphorical language, given the abstract nature of the target domain.

The next section will outline the theoretical framework before providing an overview of the Vedanta philosophy, followed by the methodology, results and conclusion.

\section{Theoretical framework}

The framework within which this research is embedded is commonly known as CMT, within the paradigm of cognitive linguistics (CL).

As a discipline that emerged in the late 1970s, one of the key characteristics that marked it, apart from what was known as 'mainstream linguistics' at the time, was the emphasis on contextually relevant language use, premised on the notion that analyses of linguistic phenomena ought to be based on empirically motivated data. Hence, a usage-based approach to language study was introduced, and authentic data became the focus of study; this marked a shift away from rationalistic 'armchair linguistics', where data were created and analysed using the researcher's intuitions (cf. Sampson 2002 for a cogent critique of the latter). With regard to this, the choice of Vivekananda's Complete Works (CW) as the domain of empirical analysis is apt, as the corpus comprises various means of communications employed; these include written epistles, transcribed talks, commentaries, poems and a few translated works, although most were presented in English originally.

One of the ostensibly revolutionary contributions made by CMT about metaphors is that they are conceptual in nature a figure of thought instead of a figure of speech. However, according to Turner (1995:179), this theory dates back to Aristotle, who argued that metaphor is 'motivated by conceptual relations'. For the purpose of this article, the standard CMT model, as put forth by George Lakoff and Mark Johnson, will serve as the theoretical basis; for a detailed overview regarding a nuanced historical overview of the theory, the readers are referred to Lakoff (2014).

According to Lakoff and Johnson (1980), who popularised the theory of CMT, the conceptual basis for metaphor entails 
some kind of cognitive mapping between two different conceptual domains, from a source to a target. To illustrate with an everyday example, the up is more and the up is better metaphors tend to associate the idea of 'up' and its spatial conceptual domain with the notion of 'an increase of quality' (Johnson 1987). These are considered the underlying conceptual metaphors, within which various linguistic manifestations of the said metaphor occur, like John is in high spirits today (meaning that he is in a good mood, perhaps) or the price of petrol is going up (referring to an increase). As a side note, in presenting the data, this article will follow the convention used by Kövecses (2010:9-10), whereby the hypothetical mapping between the source and target domains will be illustrated in the form of a table.

It has been argued that people must necessarily employ conceptual metaphors in understanding God, and their relation to him - it has also been argued that 'without metaphor abstract thought is virtually impossible' (Lakoff \& Johnson 1999:59). In fact, Lakoff (2002:246) specifically argues that literal modes of thought and literal language are 'simply not adequate for characterising God and the relation of human beings to God', and adds more generally that there is no 'fully literal interpretation of the Bible'. Related to this, Vivekananda says quite explicitly that as 'the vast majority of mankind must deal with things that are concrete', he employs various devices to illustrate his metaphysical theories, including metaphor, analogy, simile, etc. (CW1:511). Others have pointed out that 'religious language has to be figurative because it deals with conceptual domains and entities which are not conceptually and linguistically apprehensible in an immediate, direct way' (Barcelona 2003:2). Vivekananda also makes numerous references to the importance of using metaphorical language, which is why he once said to an audience that 'none of you can think without some symbol' (CW-1:230).

It is therefore in keeping with the assumption that in a domain expounding upon metaphysical assumptions in line with abstract philosophico-religious themes, metaphorical language will be rife because the need for metaphorical language would be even greater than in language used in less abstract domains.

\section{Overview of the Vedanta}

Vivekananda explicitly aligns himself to a system of philosophy known as the Vedanta. This school of thought was said to have been founded by an ancient Indian sage by the name of Vyasa. This system is based on the writings to be found in the Upanishads, and it contains the doctrines set forth in the 'closing chapters of the Vedas' (Sivananda 1977:270). Even after narrowing down the scriptural lore to refer to the Jnana Kanda ('knowledge portion') of the Vedas, excluding the Karma Kanda ('ritualistic portion'), it is worth noting that there are said to be 108 Upanishads (though in fact there are more), of which there are between 10 and 18 principal Upanishads. These are picked out as the 'principal'
Upanishads because various influential commentators took up these very texts to base their writings on. Within the Vedanta, there are three dominant sub-schools, which will be discussed briefly below.

\section{The three main schools of metaphysical thought within Vedantic philosophy ${ }^{1}$}

Vivekananda stated that the 'Vedanta philosophy, as it is generally called at the present day, really comprises all the various sects that now exist in India' (CW-1:357). Later in the same discourse, entitled the Vedanta Philosophy, he goes on to say that Vedanta really has become one and the same as Hinduism itself. The Vedanta, then, from a practical purview, forms the scriptures of the Hindus, and all systems of philosophy that are orthodox have to take it as their foundation. Vivekananda also points out that all 'our commentators, when they want to quote a passage from the scriptures, as a rule, quote from the Vedanta' (CW-1:357). The most well-known commentators on the Vedanta are Sankara, Ramanuja and Madhva. They founded the schools known as Advaita, Visishtadvaita and Dvaita Vedanta. These may be translated roughly as 'non-dualism', 'qualified non-dualism' and 'dualism', respectively. Each proponent commented on the Upanishads in his own way and built his own philosophy.

The conventional Hindu mind does not see a tripartite arrangement which perceives the world in three different ways, but rather as rungs on a ladder, each one necessary for understanding the other. A simple illustration would be someone who looks at the ocean and sees a massive body of water. The Advaita Vedantin would openly declare that there is only one ocean, and that the waves are ephemeral, constantly changing and certainly not real; the only reality is the ocean, from which the various waves emanate. The Visishtadvaita Vedantin would say that although the waves may have an ephemeral existence, as long as they are there in that form, we have to acknowledge their existence, shortlived as it may be. The Dvaita Vedantins would tell us that it is silly to imagine that waves and the ocean are the same thing. This might be true in some sense, but a surfer cannot go to the depth of the ocean and expect to surf - he needs the waves, and for him, their ontological status is given as axiomatic. The same goes for people studying wave patterns, or for children who go to the beach especially to splash in the waves. Hence, the latter is a more pragmatic philosophy, premised necessarily on dualism.

What was presented here is necessarily a gross oversimplification, but it is hoped that it helps to contextualise the current study. When the imports of the various conceptual metaphors are discussed, more specific and detailed aspects of the philosophy will be expounded upon, although it should be noted that only a small sample was selected for discussion here.

1.All non-English terms are written in italics, unless directly quoted from a source that did not do so; derivations are not written in italics, hence 'Vedantic' is written in normal font, as opposed to Vedanta. 


\section{Methodology Corpus linguistics}

According to Geeraerts (2010:84), there is a clear growth in interest 'in corpus-based and experimental studies', simply because CL aims at analysing real-life, user-based data; this being said, he adds that 'it would be an exaggeration to say that it has become the standard approach in Cognitive Linguistics'. Be that as it may, there is no doubt that CL is a powerful tool which allows us to analyse vast amounts of data in a systematic way - one that was not possible a few years ago. Teubert (2005) agrees, adding that:

corpus is considered the default resource for almost anyone working in linguistics. No introspection can claim credence without verification through real language data. Corpus research has become a key element of almost all language study. This is an indication that the paradigm of linguistics is finally becoming again more pluralistic. (p. 1)

According to Teubert (2005:2), CL 'offers a perspective on language that sets it apart from received views or the views of cognitive linguistics'. However, he later adds that 'corpus linguistics and cognitive linguistics are two complementary, but ultimately irreconcilable paradigms' (Teubert 2005:8). He says this because these paradigms aim to achieve different goals, which strengthen the case for a collaborative approach combining them. Of course, Teubert was speaking more generally, but with regard to metaphor research specifically, Gibbs (2010:6) says that 'one of the greatest advances, in my view, in metaphor research over the past ten years is the development of corpus research', and later adds that he 'would urge that all metaphor scholars incorporate corpus analyses within their respective work' (Gibbs 2010:7), a suggestion taken seriously in the current study. As mentioned earlier, with the advent of the computer, a variety of ways have been explored to mine data. With this in mind, a concordance program called AntConc was used to search through a corpus of data, comprising an e-version of The Complete Works of Swami Vivekananda ${ }^{2}$.

After the corpus was downloaded, compiled into a contiguous document and converted to an acceptable file format, a wellknown method for metaphor identification was used, which is discussed below.

\section{Metaphor identification procedure: Vrije University}

The Pragglejaz Group (2007:3) outlines a set of criteria by which metaphors can be identified. They call this the 'metaphor identification procedure' (MIP) and later updated this to 'Metaphor Identification Procedure: Vrije University (MIPVU)', to include the name of the university where this research group is based.

Essentially, MIPVU, which is a 'revised and extended version of $\mathrm{MIP}^{\prime}$, varies from the latter in the following ways:

2.For ease of reference, the format used here will be as follows: ' $c$ w-1:1' will refe to The Complete Works, Volume 1, page 1, instead of referring to Vivekananda (1977:1).
- The nuanced nature of metaphor is acknowledged, and a distinction is made between direct metaphors, indirect metaphors, implicit metaphors and metaphor flags.

- A tagging system is thereby suggested, after the text has been read, and the metaphoricity of relevant words (MRWs - or 'metaphor-related words') has been determined. $M R W$ : direct relates to words that can more or less straightforwardly be explained by some kind of cross-domain mapping; MRW: indirect relates to words that can potentially be explained in terms of some kind of cross-domain mapping; MRW: implicit relates to pronouns, ellipses, anaphors, etc., which may imply some kind of cross-domain mapping within the broader context of the said corpus ${ }^{3}$; and MFlag is used for terms which signal that some 'cross-domain mapping may be at play' (Dorst 2011:103).

- This system aims to go through the text with a fine comb, as it were, and asks the researcher to follow a 'no metaphor left behind' policy, referred to in the manual as the 'when in doubt leave it in' (WIDLII) principle (Dorst 2011:112).

- Provision is made for terms that are instances of personification, in which case the MRW should also be marked as 'possible personification' (PP) - this just flags the term as potentially explicable via non-metaphoric means.

- Finally, the rest of the manual goes into further detail regarding various issues, including decisions surrounding the basic meanings of MRWs, and how to decide if the usage in the text is 'sufficiently distinct' from its conventional use in English and so on.

This method was adapted in the current study as follows:

As the manual reading directed the concordance search, this was the first step in preparation for the manual tagging. After reading through a sample of the corpus manually, as mentioned, the metaphorical language used was noted, in line with step 1 of the MIPVU method. These metaphors were then grouped into different categories (more often than not, into either frames like water or a superordinate metaphor like up is better). The former was necessary when there was a range of disparate information, and the latter when there was more consistent detail pertaining to a particular conceptual metaphor. In keeping with step 2 (though focusing on a sample, not the entire corpus), this enabled the researcher to isolate lexical items that may or may not be linked to metaphors.

Step 3 was adapted, in that the volumes were searched for the identified water-related terms based on the manual reading, following more or less steps 1 and 2; thereafter the analysis of the concordances, using the lexical entries identified in steps 1 and 2, was done on the entire corpus of nine volumes. Hence, the method used here is a slightly tailored version of Pragglejaz's MIP/MIPVU method. As mentioned above, CMT will be used as the theoretical framework within which to analyse a body of work pertaining 3.Obviously, this means that not all metaphors will follow what some call the classic $\mathrm{X}$ is $\mathrm{Y}^{\prime}$ metaphorical structure. 
to Hindu philosophy, specifically focusing on Vivekananda's CW. Prior to using the AntConc software to mine the data, a manual reading was performed on the following texts:

- Vivekananda's addresses at the Parliament of Religions, convened in Chicago in September 1893, and published in the $\mathrm{CW}$;

- a series of lectures on the theme of 'work', and what it means within an Eastern, Hindu context - these have been compiled as a separate section in the text (and published elsewhere as a secondary text in book form) under the title Karma Yoga;

- Vivekananda's commentary on a classical Sanskrit text by the saint Patanjali, compiled into a book entitled Raja Yoga

- transcripts of 21 of Vivekananda's discourses/lectures given primarily (but not exclusively) across the USA and the UK;

TABLE 1: Tagging system used in the AntConc analysis

\begin{tabular}{ll}
\hline Tag symbol & Meaning of tag symbol \\
\hline $\mathrm{m} /$ & to indicate a direct, fairly obvious metaphorical use of a term \\
I/ & to indicate an implicit or indirect metaphor \\
& $\begin{array}{l}\text { to indicate that a metaphor-related word (MRW) is now being } \\
\text { used literally }\end{array}$ \\
& $\begin{array}{l}\text { to indicate a word that happens to appear in the data previously } \\
\text { as an MRW, but is now not being used in that sense at all, } \\
\text { making it irrelevant (like current, previously used to refer to the } \\
\text { flow of a river, now being used to refer to electricity, or in the } \\
\text { sense meaning 'contemporary'; or an instance of Ocean, where } \\
\text { it refers to the name of a newspaper) }\end{array}$ \\
\end{tabular}

- a text that came to be known as the Inspired Talks, which have been published separately, but also comprise a subsection of volume 7 of the $\mathrm{CW}$.

The above sample was chosen for manual reading with the idea of getting a representative sample of the $\mathrm{CW}$, as it includes Vivekananda's writings, as well as transcripts of his spoken discourses, to both large and smaller groups in various contexts - some ex tempore, some not. After reading through the above text(s) manually, the various metaphors were noted and grouped accordingly into related frames.

Once the frames were established, a decision was taken to search for lexical items which were used metaphorically within the water frame. The resulting concordances were then tagged using a simplified system, inspired by the MIPVU convention, illustrated in Table 1.

\section{Results and analysis}

The various metaphors that were found during the reading and manual tagging of metaphors can be grouped into various frames (see Table 2).

As is evident, metaphors from the water frame were the most pervasive, so words that were used metaphorically more

TABLE 2: An outline of the various frames found after a manual reading of sample texts from the Complete Works.

\begin{tabular}{|c|c|c|c|}
\hline Frame & Example & $\begin{array}{l}\text { Number of hits } \\
\quad(n=893)\end{array}$ & $\%$ \\
\hline Family & God is mother and has two natures, the conditioned and the unconditioned & 33 & 3.7 \\
\hline Book and/or library & All knowledge that the world has ever received comes from the mind; the infinite library of the universe is in your own mind & 28 & 3.1 \\
\hline Water & That shows that consciousness is only the surface of the mental ocean & 323 & 36.2 \\
\hline Circuit and/or conduit & $\begin{array}{l}\text { We can send electricity to any part of the world, but we have to send it by means of wires. Nature can send a vast mass of } \\
\text { electricity without any wires at all. Why cannot we do the same? We can send mental electricity. Each man is only a conduit } \\
\text { for the infinite ocean of knowledge }\end{array}$ & 19 & 2.1 \\
\hline Cyclic nature of life & Everything in the universe is struggling to complete a circle, to return to its source, to return to its only real Source, Atman & 28 & 3.1 \\
\hline Animal & The human mind is like that monkey, incessantly active by its own nature & 56 & 6.3 \\
\hline Light versus dark & The mind is in three states, one of which is darkness, called Tamas, found in brutes and idiots & 54 & 6 \\
\hline Heat & The idea of duty is the midday sun of misery scorching the very soul & 7 & 0.8 \\
\hline Fire & Like fire in a piece of flint, knowledge exists in the mind; suggestion is the friction which brings it out & 8 & 0.9 \\
\hline Physical actions & $\begin{array}{l}\text { The world is ready to give up its secrets if we only know how to knock, how to give it the necessary blow. The world is a grand } \\
\text { moral gymnasium wherein we have all to take exercise so as to become stronger and stronger spiritually }\end{array}$ & 12 & 1.4 \\
\hline Machine & $\begin{array}{l}\text { Devils are machines of darkness, angels are machines of light; but both are machines. Man alone is alive. Break the machine, } \\
\text { strike the balance, and then man can become free }\end{array}$ & 27 & 3.0 \\
\hline Power & Knowledge is power. We have to get to this power & 4 & 0.5 \\
\hline Master-slave & They will be slaves in the hands of nature, and will never get beyond the senses & 30 & 3.4 \\
\hline Building & Modern science has really made the foundations of religion strong & 14 & 1.6 \\
\hline Journey & $\begin{array}{l}\text { The grandest idea in the religion of the Vedanta is that we may reach the same goal by different paths. On reason we must } \\
\text { have to lay our foundation; we must follow reason as far as it leads, and when reason fails, reason itself will show us the way } \\
\text { to the highest plane }\end{array}$ & 19 & 2.1 \\
\hline Instruments & $\begin{array}{l}\text { Just as by the telescope and the microscope we can increase the scope of our vision, similarly we can by Yoga bring ourselves } \\
\text { to the state of vibration of another plane }\end{array}$ & 10 & 1.1 \\
\hline Vertical scale & The mind can exist on a still higher plane, the superconscious & 69 & 7.7 \\
\hline Plant & There is the lotus leaf in the water; the water cannot touch and adhere to it; so will you be in the world & 57 & 6.3 \\
\hline Institutions as traps & It is bad to stay in the church after you are grown up spiritually & 5 & 0.6 \\
\hline Bondage & $\begin{array}{l}\text { Freedom is not here, but is only to be found beyond. To find the way out of the bondage of the world we have to go through it } \\
\text { slowly and surely }\end{array}$ & 48 & 5.4 \\
\hline Food & Those that only take a nibble here and a nibble there will never attain anything & 9 & 1.0 \\
\hline Stage & This world is a play. You are his playmates & 3 & 0.3 \\
\hline School & The very reason of nature's existence is for the education of the soul & 12 & 1.3 \\
\hline Container & When this meditation has been practiced for a long time, memory, the receptacle of all impressions, becomes purified & 10 & 1.1 \\
\hline Disease & Evil thoughts, looked at materially, are the disease bacilli & 6 & 0.7 \\
\hline Accounting & We have to bear in mind that we are all debtors to the world and the world does not owe us anything & 2 & 0.2 \\
\hline
\end{tabular}


frequently informed the decision to use that lexical item as the basis of an electronic search of the entire corpus. Then, the concordances were tagged, and the metaphors that emerged were grouped into themes; from this, eight key themes emerged, namely, the Human Mind, Enlightened Beings, the Universe, Man's Place in the Universe, Swami Vivekananda's Mission, Religious Harmony, Buddhism, and the Vedanta Philosophy.

Some of the conceptual metaphors pertaining to the last emergent theme (i.e. the Vedanta Philosophy) will be presented here. Altogether, the corpus yielded 11 different conceptual metaphors within this school of thought as follows:

1. Life is a whirlpool.

2. Existence is waves.

3. The Vedantic scriptures are like an ocean.

4. Eastern thought is like dew.

5. Vedantic thought in society is activity in a water body.

6. Vedantic thought is a flood.

7. Non-Vedantic cults are ephemeral bubbles; Vedanta is a powerful life-giving current.

8. Earthly temptations are like a drink before a thirsty person.

9. Man is a vessel for God's love.

10. Materialism and spiritualism are like the rise and fall of tidal waves.

11. Creation is a façade/projection/reflection.

Because of practical constraints, only the first five of these will be briefly discussed here, in the following format: the postulated conceptual metaphor will be followed by a linguistic manifestation of that conceptual metaphor, followed by a table illustrating how the conceptual metaphor can be mapped; finally, the import of the metaphor will be presented.

\section{Conceptual metaphor 1: Life is a whirlpool}

Example: A current rushing down of its own nature falls into a hollow and makes a whirlpool, and, after running a little in that whirlpool, it emerges again in the form of the free current to go on unchecked. Man's experience in the world is to enable him to get out of its whirlpool (CW-1:58).

Import of metaphor mapped in Table 3: Birth into this world is seen as analogous to being caught up in a whirlpool, and escaping the whirlpool is tantamount to being liberated from the suffering of the world. Although it is believed that the world is ultimately unreal, it is a fact that people living in it suffer, and the suffering only ceases when people are able to escape from it. In this context, 'escape' connotes transcending the world of temptation by becoming desireless. People are

TABLE 3: Mapping for 'life is a whirlpool'.

\begin{tabular}{lll}
\hline Source: Whirlpool & & Target: Life \\
\hline Whirlpool & $\rightarrow$ & Worldly life \\
'Bound' current & $\rightarrow$ & Coming into this world; being born \\
'Free' current & $\rightarrow$ & Escaping from this world \\
Escaping whirlpool & $\rightarrow$ & Transcending the earthly life \\
\hline
\end{tabular}

born into this world to learn certain lessons which were not learnt from previous births, and are bound to suffer for the misdeeds from previous births as well. The only way to be saved from 'drowning in this whirlpool' of life is to get out of the whirlpool. As mentioned, the main way of doing so is by transcending desires and therefore attachment, because that is the primary reason for getting caught in this quagmire of life. Various methods and techniques are suggested for getting out of this whirlpool, which include the various spiritual practices that are part of every religion; within Hinduism, these can be divided into the following four paths: the path of action (karma yoga), the path of knowledge (jnana yoga), the path of mysticism (raja yoga) and the path of love (bhakti yoga). Depending on one's predispositions, a particular path is chosen and stuck to, which would ultimately, if practised properly, give one the tools to escape from the whirlpool of life. In the context of this metaphor, then, these various paths are conceptualised as 'life-savers' or being taught how to swim out of the vortex. As an aside, Vivekananda wrote a book covering each of these paths (meaning he wrote four books, one for each path), which now has become part of CW-1, although published separately.

\section{Conceptual metaphor 2: Existence is waves}

Example: According to Buddhism, man is a series of waves. Every wave dies, but somehow the first wave causes the second. That the second wave is identical with the first is illusion (CW-6:69).

Import of metaphor mapped in Table 4: Here Vivekananda actually criticises the Buddhist notion of rebirth, which has been addressed by scholars like Mason (2012:95). Rebirth is the notion which states that a person is reborn because of the impetus of his thoughts/desires from previous births, like the impetus of a wave resulting in a new wave. The critique centres around the fact that the wave cannot exist without the ocean supporting it, likewise individual souls have to be connected to something greater in order to ensure continuity.

In expounding the Vedanta philosophy, Vivekananda on more than one occasion would say that the term 'Hindu' is no longer applicable, if referring to the religion of the Indian people. He says that 'the word "Hindu" in former times was full of meaning, as referring to the people living beyond the Sindhu or the Indus', but that 'it is now meaningless' (CW-3:248). He would later add that the 'Vedanta is now the religion of the Hindus', because anyone professing to be a Hindu would have to accept the authority of the Vedantic texts, and any sage or teacher who claims to be teaching Hinduism would have to base their teachings on the Vedanta (CW-3:259). This is why the founders of the three well-known schools of Vedanta chose to interpret those specific texts in a particular way.

TABLE 4: Mapping for 'Existence is waves'.

\begin{tabular}{lll}
\hline Source: Wave & & Target: Existence \\
\hline Ocean & $\rightarrow$ & Underlying consciousness \\
Waves & $\rightarrow$ & Individual souls \\
\hline
\end{tabular}


Vivekananda is critical even of these great teachers, however, and points out that they are all guilty of what he calls 'text torturing'. With reference to Sankara, he says that 'the same commentator, as soon as a dualistic text presents itself, tortures it if he can, and brings the most queer meaning out of it', in an attempt to box those particular passages into his Advaitic theory, for example (CW-3:129). He concludes that these commentators did not appreciate the diversity of the Vedic texts, and therefore the Vedantic texts, and made the mistake of assuming that the whole of the Vedas 'spoke the same truth', and were therefore 'guilty of torturing those of the apparently conflicting Vedic texts which go against their own doctrines, into the meaning of their particular schools' (CW-7:252).

Vivekananda solves this quandary by saying that each school should be seen as a progressive step culminating in the nondualistic school. His point here in this exposition of the Vedanta philosophy was essentially a negative one, where he would follow the Socratic method of putting forth a particular theory and then showing it to be problematic at various levels, and concludes by showing how an account premised on Vedantic tenets would solve the problem.

This particular metaphor is one such critique of one of the central metaphysical purports which Buddhists adhere to, namely, that upon death what remains is nothing more than the 'impetus' left by our thought 'currents' upon death, which continue to push forth resulting in another 'wave' of existence. Vivekananda is here applying the neti neti ('not this, not that') method of philosophical analysis. When trying to understand the nature of Reality, for example, assuming that this Reality must be something which is not ephemeral, we can ask the following question: Is this table real? When one studies its structure, and comes to learn that ultimately this table will decompose and not last forever, the fact that it is not long-lasting makes it not 'real', or only temporarily real. Likewise with the human body: Is the human body real? The Buddhist answer is that not only is this body not real, but neither is the mind or the soul; they all have a temporary existence which is there only for the duration of one's lifespan. The difference between this take on the nature of human beings and that of the Vedanta is that the latter claims that there must be some underlying sense of continuity if the person who was a baby, a 10-year-old child and an adult today is to call himself the same person, as the body and the mind have been changing all the time throughout.

Vivekananda here is therefore asking the question: why do we not accept the claim made by the Buddhist philosophers which state such a thing? What is the need to postulate a soul, and to further make the claim that this soul is more than the mere impetus of one's thoughts, but an eternal entity which is part and parcel of the underlying Unified Consciousness which pervades the entire cosmos?

There is no doubt that the thought currents which originate in the mind have a certain impetus, which seems to have almost a palpable effect on the environment and the body sometimes, but there is a serious lacuna in this assumption if one does not accept that there is more to existence than that. For example, if one has a very intense dream, and it seems to last for a long time, we notice that upon waking everything that existed in that dream simply vanishes, except for the residual thoughts and feelings that are still with you - if it was a scary dream, perhaps one would have an elevated heart rate, etc. When one awakens, it may take some time to adjust to the phenomenal world, but then the question arises: how real is this existence? It is logically possible that those experiences post-waking could also be a dream-like experience. Be that as it may, the point is that in both the waking state and dream state, the same consciousness is common to both. There is even a third state of consciousness, in deep sleep, where one neither dreams nor is conscious of anything. The question then arises as to what the common factor is to all three states of consciousness. If it was merely the impetus generated from the preceding state, it does not explain the continuity of existence all round.

Therefore, Vivekananda points out that, according to the Vedanta, there is a fourth state of consciousness which is both immanent in, and transcendent of, the other three states. However, because this state is 'running in the background', as it were, providing the scaffolding or the basis for the manifestation of others, it is not something one is directly aware of, like fish are perhaps not aware of the water sustaining them. This fourth state goes by the name turiya ('superconscious state') in Sanskrit.

Using a water analogy: if one considers a lake, and looks at a ripple, a wave and a whirlpool in that lake, and makes the claim that all that there is to an individual whirlpool is its temporary existence, which disappears after it stops, except for the momentum of the whirlpool which can manifest as another whirlpool elsewhere in the lake, then that would be analogous to the nihilistic Buddhistic conception of existence. However, there is something common to all three forms, which is the water itself, which is separate from the ripple, whirlpool and wave, and yet once it morphs into those shapes one perceives them as ostensibly separate.

Turiya, this fourth state, is like the water in the abovementioned example, being the underlying 'thing' that is common to all manifestations. On this basis, Vivekananda rejects the import of the metaphor used and says that the Buddhists have a serious gap in their metaphysics, and ought to fill the gap by accepting turiya as a logical necessity. This is one of the many arguments put forth in defence of the Vedantic notion justifying an underlying Reality, which acts as the scaffolding of the universe. This is why Vivekananda says that the metaphysical philosophy of the Buddhists was found wanting, because 'the disciples of the Great Master dashed themselves against the eternal rocks of the Vedas and could not crush them', and therefore 'Buddhism had to die a natural death in India' (CW-1:18). 


\section{Conceptual metaphor 3: The Vedantic scriptures are like an ocean}

Example: Even the Jnana Kanda of the Vedas is a vast ocean; many lives are necessary to understand even a little of it (CW-3:226).

Import of metaphor mapped in Table 5: The scriptural texts within Hindu philosophy are vast; this metaphor speaks to that point, meaning that the vast body of scriptural lore within the Hindu tradition can be very intimidating to a scholar or spiritual seeker wanting to study even the core Hindu texts. The implication here is partly to point to the necessity of an experienced mentor (a guru) for one who wishes to tread the spiritual path.

Vivekananda points out that:

... all our great philosophers, whether Vyasa, Patanjali, or Gautama, and even the father of all philosophy, the great Kapila himself, whenever they wanted an authority for what they wrote, every one of them found it in the Upanishads, and nowhere else, for therein are the truths that remain forever. (CW-3:226)

In fact, he further claims that 'what we really mean by the word Hindu is really the same as Vedantist', meaning that anyone who calls himself Hindu should owe allegiance to the Vedanta (CW-3:227), as mentioned above. With reference to the Jnana Kanda of the Vedas, Vivekananda says that this has 'become the Bible of modern India' (CW-3:226).

Essentially, they all drive at the same point, but they are very literary at times, and some are rather lengthy philosophical treatises, generally based on the Hegelian dialectic 'of thesis, antithesis and synthesis' (Krishnananda 1994:86).

Furthermore, aside from the texts themselves, there are ancillary texts which are to be studied in preparation for the study of the actual texts. These are the Vedangas, roughly referring to the 'preparatory limbs' of the Vedas, and the Upa Vedas, meaning subsidiary Vedic texts.

There are six key Vedangas: the Siksha, referring to the science of pronunciation and intonation; Vyakarana, which gives a grounding in the grammar of language; Chhandas, which train one in the metre in which the hymns are composed; Nirukta, which gives a background to the etymology of words and meanings in the Vedic texts; Jyotisha, referring to the science of astronomy; and, finally, Kalpa, which is a manual of ritualistic practices. The latter is further divided into the Srauta, Grihya, Dharma and Sulba Sutras, meaning 'the rules regarding Vedic sacrifice, domestic sacrifice, human conduct, and the principles of laying out sacrificial altars, and the like' (Krishnananda 1994:86). Many scholars also state that

TABLE 5: Mapping for 'the Vedantic scriptures are like an ocean'.

\begin{tabular}{lll}
\hline Source: Ocean & & Target: Vedantic scriptures \\
\hline Ocean & $\rightarrow$ & Vedantic lore \\
Waves & $\rightarrow$ & Subsidiary texts \\
\hline
\end{tabular}

Panini's classic, the Ashtadhyayi, which is one the of earliest works on Sanskrit grammar, comprising nearly 4000 aphorisms pertaining to classical Vedic Sanskrit (Mukherjee 1999:28), is one of the key Vedangas.

The Upa Vedas are like appendices to the Vedas. The Ayurveda, for example, is a medical text which forms part of the Rig Veda and is concerned with the prevention and cure of diseases; the Dhanurveda is the science of archery and warfare and forms part of the Yajur Veda; the Gandharva Veda is the art of music and belongs to the Sama Veda; finally, the Artha Sastra is the science of economics, politics and statecraft and forms part of the Atharva Veda.

A serious study of the Upanishads, according to Hindu customs, requires 12 years of mentorship under a qualified guru, and from the above discussion, it is clear why. This is why Vivekananda refers to the Upanishads as a 'vast ocean', and should perhaps have added that a mentor could serve as a life-boat on this ocean and that the various preparatory texts could serve as gentle 'waves' with which you 'wet your feet' before plunging into the ocean. If one delves into this ocean without any assistance, however, he would almost inevitably find himself lost.

\section{Conceptual metaphor 4: Eastern thought is like dew}

Example: Slow and silent, as the gentle dew that falls in the morning, unseen and unheard yet producing a most tremendous result, has been the work of the calm, patient, all-suffering spiritual race upon the world of thought (CW-3:61).

Import of metaphor mapped in Table 6: Unlike the flood connotation, the point here is that the ideals of Vedanta will influence the world in a powerful, yet surreptitious way. With regard to this, Vivekananda quotes Schopenhauer who said that ' $[t]$ he world is about to see a revolution in thought more extensive and more powerful than that which was witnessed by the Renaissance of Greek Literature' (CW-3:61). He later says that the dew, despite being so gentle and benign, has the ability to break the mightiest mountain to pieces by infiltrating the cracks without the mountain even 'realising'. Aside from the claim that Indian thought in general will gently yet powerfully overcome the dogma which at the time was fast becoming the fad of materialism, atheism, agnosticism and Mammon-worship, he further goes on to say that the world will experience a 'never-ceasing permeation of Indian thought' (CW-3:61), and will thereby be given succour from the suffering that would otherwise come as a necessary upshot to the way things were going at the time.

TABLE 6: Mapping for 'Eastern thought is like dew'.

\begin{tabular}{lll}
\hline Source: Dew & & Target: Eastern thought \\
\hline Dew & $\rightarrow$ & Eastern/Vedantic thought \\
Plants being nourished & $\rightarrow$ & People benefitting spiritually \\
Mountains & $\rightarrow$ & $\begin{array}{l}\text { Dogmatic traditions (including } \\
\text { materialistic science) }\end{array}$ \\
\hline
\end{tabular}




\section{Conceptual metaphor 5: Vedantic thought in society is activity in a waterbody}

Example: I fully believe that there are periodic ferments of religion in human society, and that such a period is now sweeping over the educated world. Whilst each ferment, moreover, appears broken into various little bubbles, these are all eventually similar, showing the cause or causes behind them to be the same. That religious ferment which at present is every day gaining a greater hold over thinking men has this characteristic that all the little thought-whirlpools into which it has broken itself declare one single aim - a vision and a search after the Unity of Being (CW-8:207).

Import of metaphor mapped in Table 7: Vivekananda refers here to the fledgling stages of a society which is about to switch from being materialistically minded to more spiritually minded, which will increase the more this metaphorical fermentation process takes place.

Although the metaphors are a bit mixed here, they are mostly taken from the same context, which is a letter that Vivekananda wrote to a friend in August 1895, whilst in New York. By this time, Vivekananda's fame had spread all over the USA, and newspapers were reporting favourably on his speeches; he was therefore a known figure having been actively preaching for the past two years following his debut speech in Chicago on 11 September 1893.

Here, Vivekananda compares society to something that is fermenting. Although this word, when used metaphorically, conventionally has a negative connotation, Vivekananda does not mean it negatively. Taken literally, it refers to a chemical process where one substance, like juice, is turned into another substance, like beer or wine. This is typically a slow process and requires not only patience but also an environment that is conducive to sustaining the process - this would be a constant temperature, a dark room, ingredients (like yeast) which initiate the process, and so on. As with something that is in the process of fermenting, the longer one leaves it, the better the product.

One could understand this to imply that the society which Vivekananda is referring to is in the fledgling stages of a new beginning. Society in Vivekananda's time was very materialistic, and spirituality was taking a back seat in many

TABLE 7: Mapping for 'Vedantic thought in society is activity in a waterbody'.

\begin{tabular}{|c|c|c|}
\hline $\begin{array}{l}\text { Source: Activity in a } \\
\text { waterbody }\end{array}$ & & Target: Vedantic thought \\
\hline Process of fermenting & $\rightarrow$ & Process of spirituality influencing society \\
\hline Bubbles & $\rightarrow$ & $\begin{array}{l}\text { Pockets of society taking up the call of } \\
\text { leading a spiritually inspired life }\end{array}$ \\
\hline Whirlpools & $\rightarrow$ & $\begin{array}{l}\text { Individuals being influenced by the } \\
\text { zeitgeist of spiritual rejuvenation }\end{array}$ \\
\hline Tree & $\rightarrow$ & Humanity \\
\hline Roots & $\rightarrow$ & $\begin{array}{l}\text { Belief systems which inspire and sustain } \\
\text { humanity }\end{array}$ \\
\hline Watering the roots/tree & $\rightarrow$ & Propagating spiritual ideals \\
\hline Process of melting & $\rightarrow$ & Joining society in a uniform cause \\
\hline Wave & $\rightarrow$ & $\begin{array}{l}\text { Uniform influence the culmination of the } \\
\text { spiritual zeitgeist will have }\end{array}$ \\
\hline
\end{tabular}

respects, with religion being scorned on the basis of being akin to anachronistic superstition. 'Scientism', as it has been called, was becoming increasingly prominent, but Vivekananda is saying here that societies go through these phases on a continual basis, where spiritual fervour builds up slowly in response to a need, that need being the lacuna left by rank materialism. As this materialism takes over the ethos and moral norms governing individuals in society, people become more and more self-centred, eventually causing that society to collapse. Vivekananda said on numerous occasions that ' $[t]$ he whole of the Western world is on a volcano which may burst tomorrow', and later uses another metaphor to say that they have 'drunk deep of the cup of pleasure and found it vanity', and that the time is now ripe for 'India's spiritual ideas' to 'penetrate deep into the West' (CW-3:163). Though said in another context, Vivekananda is driving at the same point: just as the fermentation process is slow, it eventually builds up and starts 'bubbling', culminating in a new product altogether. The instigating factor for this fermentation process was arguably the two world wars which followed Vivekananda's death, which could be the 'bursting' he had some kind of premonition about. This could be what initiated the fermentation process in Vivekananda's metaphor. If one thinks about brewing something, one would need some substance to get the process started, so an amount of sugar would need to be mixed with yeast in an anaerobic environment, at a temperature conducive to the yeast being 'activated'; this could be the source domain logically entailed by the metaphor, being mapped onto the events of the world wars, which made people ask the bigger questions in life, like who they are, and what is the meaning of this earthly existence.

After these events, we can understand the introspection that was inspired by the deaths and human suffering as the 'brewing process' which is currently underway. The 'bubbles' in the brewing process are those people who are responsive to the circumstances the world is in, in other words, those who have started to introspect and turn to spirituality. These people will increase as time goes on, and Vivekananda says that these people are like little whirlpools which start at the beginning of this process, but these 'melt away' and merge into society, but provide the impetus for a massive 'wave' which will come forth and revolutionise society. Elsewhere, Vivekananda says that this is the collective energy that society harnesses and manifests in the form of a revolutionary spiritual leader - a prophet.

Later on in this letter, Vivekananda uses another metaphor to make a slightly different point. He says that we need to stop seeing the world as disparate nations, and in fact serving one's country, we should see as service to the world, as the Vedantic worldview says that we are all part of the greater whole, meaning that we should not see ourselves as separate entities, whether as individuals, societies or as a sense of national pride. This fermentation process, then, is not one which affects individuals, but will affect every other nation and therefore the world. This is what is meant by the entire tree being benefitted by the root being watered. 
Likewise, the Christian concept of 'loving thy neighbour' makes a lot of sense, except none has ever 'given the reason' for doing or not for doing so (CW-1:219). The reason from a Vedantic perspective is quite simple that we should think like that because one should see oneself as the same as one's neighbour, meaning that loving one's neighbour is tantamount to loving oneself, just as the tree cannot be separated from the individual roots. Referring to the previous metaphor, it is clear how Vivekananda sees the whole world as being part and parcel of the same body of liquid; so when this fermentation process comes to a climax, the entire body bubbles and changes the very nature of the liquid, like from juice to wine, for example; likewise, the whole world is transferred from a materialistic mindset to a spiritually enlightened one, and the whole world is taken on this journey collectively. This is why the process of 'melting' and becoming one with the society towards the common cause should not be frowned upon because individuality is a falsity premised on a false perception, according to Vivekananda's Advaita Vedanta.

\section{Conclusion}

One must revisit the research question posed in the beginning: what are the specific metaphors that Vivekananda used to explain the nuances of the Vedanta philosophy in bringing it to the West?

It was demonstrated that Vivekananda uses metaphors from various frames, and a manual reading of a sample of texts from $\mathrm{CW}$ revealed that there are 26 frames within which the various metaphors fall. The various frames were illustrated in Table 2, together with the number of hits in the corpus, and an example of a linguistic manifestation of the various underlying frames. This is, however, not a closed list, and perhaps a closer reading would reveal more frames. Some frames draw on nature, like plant, whereas others draw on institutions, like school. Many of these frames were not productive at all, like heat, fire, conduit, physical actions and power. Superordinate metaphors like 'logical reasoning' is a guide and institutions as traps were also not productive, and these frames/superordinate metaphors all featured in less than $1 \%$ of the sample texts. Although there was a variety of conceptual metaphors used under each frame listed, the most productive frame proved to be water; hence, the decision to focus on the specific metaphors used within that frame. The metaphors analysed in this article were as follows:

1. Life is a whirlpool.

2. Existence is waves.

3. The Vedantic scriptures are like an ocean.

4. Eastern thought is like dew

5. Vedantic thought in society is activity in a waterbody.

This article provided an analysis of these metaphors, followed by an explanation of the import of each. Although the analysis was done with the intention of expounding upon the import of these metaphors, the mappings as they occur in the linguistic representations of underlying conceptual metaphors should be foregrounded. The various imports of these metaphors were explained in light of Vivekananda's teachings, at least bearing in mind the crux of his CW, if no direct references were made.

It is evident that Swami Vivekananda's use of water metaphors is indeed quite telling, and provides a novel and interesting base from which to explore his thinking and philosophy.

It may be worth noting that 'frame' may be a misnomer in this context, as water-related concepts can be seen as higher level, abstract superordinate conceptual metaphors, although that would be a matter of definition which requires some justification.

Neo-Hinduism, including the practice in South Africa, has moved on from the Vedic orthodoxy it once was. Whilst it is widely accepted that Swami Vivekananda played a key role in this, it has never really been explained how he accomplished this, aside from the fact that he travelled widely, and spoke to a variety of audiences around the world; of course, the organisation and formation of the Ramakrishna Math and Mission is an obvious upshot of his work as well. However, the specific techniques used to persuade his audiences of the philosophical ideology, known as the Vedanta, have not been given much attention. More especially, his use of metaphor in general to explain and convince people is put forth here as a key tool that he employed to get his ideas out into the world, and to form the intellectual basis of the movement he started - with other neo-Hindu movements following in his footsteps.

From a CL perspective, CMT is shown to be a quite useful theoretical framework to analyse and understand the underlying conceptual devices at play in Vivekananda's thinking. Corpus Linguistics as a tool allowed for the electronic mining of hundreds of pages of (approximately 4500 pages) of data, which is not practical, or even possible, without the use of concordance software. This study has also shown that in a corpus dealing with abstract religious themes, one can expect a proliferation of metaphorical language, making it a rich avenue for future research in the field of metaphor studies.

\section{Acknowledgements Competing interests}

The author declares that he has no financial or personal relationships that may have inappropriately influenced him in writing this article.

\section{References}

Barcelona, A., 2003, 'The metaphorical and metonymic understanding of the Trinitarian dogma', International Journal of English Studies 3, 1-27.

Dorst, A.G., 2011, Metaphor in fiction - Language, thought and communication, Uitgeverij BOXPress, Oisterwijk.

Geeraerts, D., 2010, 'Recontextualising grammar: Underlying trends in thirty years of cognitive linguistics', in E. Tabakowska, M. Choinski \& L. Wiraszka, L. (eds.), Cognitive linguistics in action: From theory to application and back, pp. 71-102, De Gruyter Mouton, Berlin. 
Gibbs, R.W., 2010, 'The wonderful, chaotic, creative, heroic, challenging world of researching and applying metaphor: A celebration of the past and some peeks
into the future', in G. Low, Z. Todd, A. Deignan \& L. Cameron (eds.), Researching into the future', in G. Low, Z. Todd, A. Deignan \& L. Cameron (eds.), Researching
and applying metaphor in the real world, pp. 1-20, John Benjamins, Philadelphia.

Harrison, V.S., 2015, 'Seeing the Dao: Conceptual metaphors and the philosophy of religion', Religious Studies 51(3), 307-322. https://doi.org/10.1017/S00344125 15000244

Johnson, M., 1987, The body in the mind - the bodily basis of meaning, imagination, and reason, University of Chicago Press, Chicago, IL.

Kövecses, Z., 2010, Metaphor - a practical introduction, 2nd edn., Oxford University Press, Oxford.

Krishnananda, S., 1994, A short history of religious and philosophic thought in India 3rd edn., Divine Life Society Press, Rishikesh.

Lakoff, G., 2002, Moral politics: How liberals and conservatives think, 2nd edn., University of Chicago Press, Chicago, IL.

Lakoff, G., 2014, 'Mapping the brain's metaphor circuitry: Metaphorical thought in everyday reason', Frontiers in Human Neuroscience 8, 1-14. https://doi. org/10.3389/fnhum.2014.00958

Lakoff, G. \& Johnson, M., 1980, Metaphors we live by, University of Chicago Press, Chicago, IL.
Lakoff, G. \& Johnson, M., 1999, Philosophy in the flesh: The embodied mind and its challenge to Western thought, Basic Books, New York.

Mason, G., 2012, 'The relation of akasa to pratityasamutpada in Nagarjuna's writings', $\mathrm{PhD}$ thesis, Dept. of Religious Studies and Arabic, University of South Africa.

Mukherjee, S., 1999, A dictionary of Indian literature, Orient Longman, Hyderabad.

Prabhananda, S., 2009, The early history of the Ramakrishna Movement, Sri Ramakrishna Math, Chennai.

Pragglejaz Group, 2007, 'MIP: A method for identifying metaphorically used words in discourse', Metaphor and Symbol 22, 1-39. https://doi.org/10.1080/109264 80709336752

Sampson, G., 2002, Empirical linguistics, Continuum, London.

Sivananda, S., 1977, All about Hinduism, Divine Life Society Press, Rishikesh.

Teubert, W., 2005, 'My version of corpus linguistics', International Journal of Corpus Linguistics 10, 1-13. https://doi.org/10.1075/ijcl.10.1.01teu

Turner, M., 1995, 'As imagination bodies forth the forms of things unknown', Pragmatics and Cognition 3(1), 179-185.

Vivekananda, S., 1977, The Complete Works of Swami Vivekananda, vol. 1-9, Mayavat Press, Kolkata. 